\title{
XLVII. A theory of Mr. Crookes's radiometer
}

\section{Professor Challis M.A. F.R.S. F.R.A.S.}

To cite this article: Professor Challis M.A. F.R.S. F.R.A.S. (1876) XLVII. A theory of Mr. Crookes's radiometer , Philosophical Magazine Series 5, 1:5, 395-397, DOI: 10.1080/14786447608639057

To link to this article: http://dx.doi.org/10.1080/14786447608639057

$$
\text { 曲 Published online: } 13 \text { May } 2009 .
$$

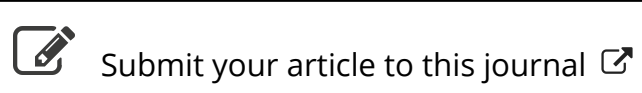

\footnotetext{
Џll Article views: 2
}

Q View related articles $\sqsubset$ 
There was no perceptible effect that could be attributed to earth-currents. The mean loss of time before the signal on make of current was visible, was 1.34 sec., and that before break of current signal was $1.28 \mathrm{sec}$, the mean being 1.31 sec., which is, as noticed, remarkably close to Mr. Varley's estimate of $1 \frac{1}{4}$ sec. The final longitude of Mokattam from Greenwich was $2^{\mathrm{h}} 5^{\mathrm{m}} 6^{\mathrm{s}} \cdot 32$; the results of the four different nights agreed very closely, the seconds from the observed times and signals uneorrected for personal equation being $6 \cdot 55,6 \cdot 64$, $6 \cdot 61$, and 6.55 , an accordance which exceeded all expectation. It would appear from this that the longitude was probably correct within two or three hundredths of a second; but it is to be borne in mind that, although there is strong evidence of the personal equations of the observers having remained very constant throughout the nights of the experiment, the amount of each could only be obtained at Greenwich after the return of the expedition, when slight alterations might have taken place in them.

From Mokattam the longitudes of the Suez and Thebes stations were easily obtained; and the work was carried further to the east by. Mr. Gill, of Lord Lindsay's party, who, with the Germans, determined the longitude of Suez and Bombay.

XLVII. A Theory of Mr. Crookes's Radiometer. $B y$ Professor Challis, M.A., F.R.S., F.R.A.S.**

I ASSUME that the construction of the radiometer and the 1 phenomena it presents are well known. In the Philosophical Magazine for January 1857 I have proposed a "Theory of the Transmutation of Rays of Light," which bears in an essential manner on the explanation of the radiometer I am about to propose; and I have made additional remarks on the same question in the Philosophical Magazine for May 1865. According to the views adopted in those communications, rays of light incident on opaque substances are partly reflected without undergoing transmutation and are partly intromitted. The latter part are transmuted into rays of the lind which by their dynamical action produce heat of temperature as distinct from radiant heat. This is what takes place on the bright side of each revolving vane of the radiometer. We may assume that the same quantity of light is incident on the blackened side as on the other; but because, as the surface is black, none of the light is regularly reflected, it follows that the whole is transmuted into the heat of temperature. The accession of temperature is therefore greater on the black than on the bright * Communicated by the Author. 
surface. The incident light thus produces an abnormal state of the atoms at and near the superficies of the vane, analogous in some degree to the state of the superficial atoms of a body electrified by friction. Such disturbance of the atoms at the surface must be accompanied by change in the interior, having the effect of causing the atoms to be somewhat more crowded together at one part than at another. (See on these points the article on the Force of Electricity in the Philosophical Magazine for October 1860, and the Theory of Electric Force in 'The Principles of Physics,' pp. 505-555.) With respect to the vanes of the radiometer in their state of continuous perturbation as to temperature, it is clear that the crowding of the atoms will be towards the bright or cooler surface, and that there will be an abnormal increment of density, regular or not, from the blackened to the white surface.

This being admitted, I may proceed to state the theory which I have elsewhere proposed for accounting for the maintenance of the interior gradation of atomic density. I consider that this theory is best given in a "New Discussion of the Hydrodynamical Theory of Magnetism," contained in the Philosophical Magazine for June 1872; but it should be noticed that in a magnet the interior gradation of atomic density results from the peculiar constitution of hardened steel, and not from abnormal superficial conditions. The case of our problem is more analogous to the production of thermo-galvanic currents by Seebeck's experiment. In any case, however, of such gradation the theory supposes that atomic repulsion acting from denser towards rarer parts is equilibrated by molecular attraction acting from rarer towards denser parts. According to the hydrodynamical theory of Attractive and Repulsive Forces (which is given more completely in the Philosophical Magazine for September 1872 than in my previous discussions of it), these forces result from the dynamical action of atherial undulations-those of small breadth and intensity causing repulsion in the direction of their propagation, and those of which the breadth and maximum intensity are large, causing attraction in the direction opposite to that of propagation. Now in all cases of the equilibration of a congeries of atoms by these opposing forces, when terms including the square of the velocity of the æther are taken into account, the mathematical reasoning (as given in the Philosophical Magazine for June 1872) shows that the æther itself is accelerated by reason of the contraction of channel due to the constancy of magnitude and form of the atoms, and the increment of their number towards the denser parts. These impressed accelerations maintain a steady circulating motion in the midst of the æther, which is always tending, by the inertia of its unlimited mass, to put a stop to such motion. According 
to the known law of steady motion, the density and pressure of the fluid are greater as the motion is less. Now in the case of the ætherial current maintained by the variation of atomic density in the radiometer's vane, the direction will be transverse to the parallel surfaces of the vane, and the motion will be least near the black surface because, by reason of excess of temperature, the channel will there be greatest. Hence there will be a decrement of cetherial density from the dark towards the bright surface, and the atoms, being immersed in this variation of density, will be urged as if the vane were pushed on the black surface. This agrees with the fact as observed. (It is proved in art. 33 of the communication in the Philosophical Magazine for September 1872, that the acceleration of an atom resulting from the variation of density of the æther has a constant ratio to the acceleration of the fluid where the atom is situated.)

Having surmised from the foregoing theory that the rotation of the vanes might be affected by the streams of a magnet in the neighbourhood of the radiometer, I found on trial that this is the case, the rate of revolution being much reduced by the proximity of a magnet of considerable power. This result might be due to the influence of the magnet's streams on those which, according to our theory, cross the vanes transversely, and may be taken to be evidence of the actuality of the latter streams.

The theory shows that the vanes are impelled by a constant accelerative force so long as the same quantity of light falls on them. But from observation it appears that for a certain quantity of incident light they attain a certain rate of revolution and then cease to be accelerated. How is this fact to be explained? It is evident that there must be some amount of friction between the glass support and the pivot on which the system of vanes turns; and this, together with the resistance which would be produced by ever so small a residuum of air in the glass globe, may sufficiently account for a limit to the rate of revolution. As respects friction, this explanation appears to be confirmed by a peculiar circumstance which has been very recently noticed-namely, that when the glass globe is caused to float in water and the motion of the ranes is stopped, on throwing light upon them the globe is observed to rotate. The reason seems to be that the accelerative forco which by the incidence of light is made to act on the vanes, takes effect, by the intervention of friction, so as to move the globe. It is evident that the tendency of the friction is always to make the globe partake of the rotatory motion of the ranes. I give this explanation with reservation, not having yet seen a complete account of this novel experiment.

Cambridgo, April 21, 1875. 